\section{Colonoscopy as best screening test not proven}

The Canadian Task Force on Preventive Health Care recommends testing of fecal occult blood or flexible sigmoidoscopy for patients at average risk of colon cancer. ${ }^{1}$ The guideline states that there is not enough evidence for colonoscopy as a primary populationbased screening test. This does not mean that the task force thinks colonoscopy will not save lives; it means only that, to date, there are no randomized controlled trials that prove it.

Colonoscopy is considered the gold standard for colon investigation. Indeed, if anything is found on fecal occult blood or by sigmoidoscopy, patients are referred for colonoscopy. It is the test advised for higher risk patients with a family history of colorectal cancer. ${ }^{2}$ Randomized control trials for colonoscopy as the primary screening tool have not been done in the United States, because it was considered unethical to assign people randomly to not to receive a colonoscopy. There are trials underway in Canada, Europe and the US, but it will be years before the results are available. There are many case-control studies showing a clear benefit of colonoscopy. ${ }^{3}$ The concern is that, while we are waiting for prospective studies, patients may be denied a test that will likely save more lives than fecal occult blood tests or flexible sigmoidoscopy.

As gastroenterologists, we would rather find polyps, the source for most cancers. Colonoscopy is able to detect and remove polyps so that cancer does not develop in the first place. The other tests find only some colon cancers, and certainly miss others, especially early ones.

The task force suggests that colonoscopy does harm. ${ }^{1}$ The 1:1000 published perforation rate during colonoscopy (about three times less in Ontario) is more likely to occur if a therapeutic manoeuver, such as polyp- ectomy, has taken place. This is done in about one-third of cases. Because the incidence of colon cancer (1:19) far outweighs risk associated with colonoscopy, we are concerned that there could be more harm done when cancers are missed by inferior tests.

In the end, all patients should discuss these issues with their family doctors. Although we appreciate that there may be long wait lists for colonoscopy, there are some parts of Canada where colonoscopy is more readily available, and it should be discussed as one of the options.

It is important that all those aged between 50 and 75 are screened for colon cancer. Screening should be done earlier if there is a family history of colon cancer. Doing any test is better than doing nothing at all. Symptoms such as bleeding, change in bowel habits, abdominal pain or weight loss need to be investigated at any age. Time will tell if the best screening test is colonoscopy.

\section{Iain Murray MD CM MSc}

Board of Directors, Ontario Association of Gastroenterology, Markham, Ont.

\section{References}

1. Canadian Task Force on Preventive Health Care. Recommendations on screening for colorectal cancer in primary care. CMAJ 2016;188:340-8.

2. Winawer S, Fletcher R, Rex D, et al.; Gastrointestinal Consortium Panel. Colorectal cancer screening and surveillance: clinical guidelines and rationale update based on new evidence. Gastroenterology 2003; 124:544-60

3. Pan J, Xin L, Ma YF, et al. Colonoscopy reduces colorectal cancer incidence and mortality in patients with non-malignant findings: a meta-analysis. Am J Gastroenterol 2016;111:355-65.

CMAJ 2016. DOI:10.1503/cmaj.1150117

\section{Palliative care most effective when invisible}

Zimmerman has effectively shown that the stigma around the word "palliative" is the main barrier to access for patients who could benefit from palliative care. ${ }^{1}$ In a related commentary, Caprio considers that renaming it "supportive care" might help. ${ }^{2}$
My experience as a family physician with a focused practice in hospice palliative care included attending over 1000 patients and their families who were referred to me during the final stages of their lives. Some died in a few days. Many were with me for a year or more. I can count on my fingers and toes the ones who came into the process with an acceptance and willingness to focus on dying, asking for palliative care by its name. However, most were looking for pain and symptom relief and a bit of practical strategy and hope so that they could keep managing their lives until overtaken by the inevitable.

The discipline of hospice palliative care has grown over the past 25 years to awaken society and the profession to the need for a comprehensive approach to the patient's experience of their condition from beginning to end.

I believe this is almost achieved, and it is time to smudge out the separation between stages of care and stop trying to name and attribute those phases to a group of practitioners or settings of care. The profession needs to own the responsibility for knowing and managing its patients' experiences of the effects of their conditions, with help from those with special expertise. When palliative care becomes invisible because it is completely ubiquitous in our practices and the system, our mission will have been achieved.

Thank you to all who continue to stand with their patients and others with hope and perseverance in the pursuit of life until death.

Nancy M. Merrow MD

Orillia Soldiers' Memorial Hospital, Orillia, Ont.

\section{References}

1. Zimmermann C, Swami N, Krzyzanowska M, et al. Perceptions of palliative care among patients with advanced cancer and their caregivers. CMAJ 2016;188:E217-27.

2. Caprio AJ. Palliative care: renaming as supportive care and integration into comprehensive cancer care. CMAJ 2016;188:711-2.

CMAJ 2016. DOI:10.1503/cmaj.1150118 